\title{
EFFECT OF DIE AND PUNCH RADIUS ON SPRINGBACK OF STAINLESS STEEL SHEET METAL IN THE AIR V-DIE BENDING PROCESS
}

\author{
M.S. Buang ${ }^{1}$, S.A. Abdullah ${ }^{1,2 *}$ and J. Saedon ${ }^{1}$ \\ ${ }^{1}$ Faculty of Mechanical Engineering, Universiti Teknologi MARA, \\ 40450 Shah Alam, Selangor \\ *Email: shahrulazam@ salam.uitm.edu.my \\ Phone : +603-55435161; Fax : +603-55435160 \\ ${ }^{2}$ CADEM Center, Faculty of Mechanical Engineering, Universiti Teknologi MARA, \\ 40450 Shah Alam, Selangor
}

\begin{abstract}
This paper focuses on the effect of the die and punch radii on the springback in the air V-die free bending process of stainless steel sheet metal. The experiment was performed on sheet metal using various die and punch radius values while their springback behavior was observed. The design of experiment approach was used in these experiments using the full factorial and analysis of variance methods to identify whether or not the die and punch radii are significant input parameters in predicting springback. From the statistical analysis, it shows that the die and punch radius parameters are significant factors contributing to the springback effect in the V-die bending of stainless steel sheet metal at the significance level of 0.05 because their $p$ value is less than 0.05 . The results from the experiments showed that springback is affected by the die and punch radius values in the air V-bending experiments. From this analysis, it can be concluded that the springback values can be decreased by decreasing the values of the die and punch radii. In the air $\mathrm{V}$-die bending process, the punch radius is the most important factor to be considered. The experimental method agreed well with the design of experiment results.
\end{abstract}

Keywords: Stainless steel sheet metal; springback; die and punch radii; air V bending; design of experiment.

\section{INTRODUCTION}

The bending and forming of sheet metal is an important process in manufacturing industry in the production of automobiles, aircraft and the casings for electronic parts. Bending is the manufacturing process where sheet metal is plastically deformed to change its shape. To produce a bend in the finished part, applied bending force must exceed the yield strength of the material to ensure the material retains a permanent set or bend when the load is removed. In this condition, springback or elastic recovery will occur. Springback is generally defined as an elastically recovered change in shape of the finished part during the removal of forming loads [1]. The springback phenomenon occurs during the bending process due to the many process parameters, such as die radius, punch radius, die gap and punch travel, with various degrees of modification to the bending angle [2]. Common bending in the sheet metal process produces a $\mathrm{V}$ shape [3], U-shape or channel shape [4] about one forming axis only. The simplest type of bending process is air $\mathrm{V}$ bending. In the air $\mathrm{V}$-bending situation, the workpiece to be 
bent at the required angle is supported on each side of the bend and a load is applied to a forming punch in the center by adjusting the depth to accomplish the work. The workpiece is not forced to contact the bottom of the die cavity. It leaves a space or air underneath. The main advantage of choosing the air bending process is the variance and the large-range band angle that can be produced with one tool set [5]. Moreover, studies on the design of the process parameters on springback are limited. Several researchers have studied springback using the design of experiment (DOE) method [6-8]. In this paper, full factorial and the analysis of variance (ANOVA) methods in DOE are used to examine the significance of the process parameters, including punch and die radii, die opening, punch travel and punch velocity in relation to the springback. ANOVA is a statistical technique used to investigate and model the relationship between a response variable and one or more independent variables. In this paper, the objective is to study the effects of die and punch radii on springback in the air V-die bending process of stainless steel sheet metal by conducting experiments. The final bend angle in the air bending from the experiments was also analyzed statistically using the full factorial and ANOVA methods in DOE to identify whether or not the die and punch radii values are significant as input parameters to predict springback.

\section{EXPERIMENTAL WORK}

\section{Experimental procedure}

The sheet metal used in this experiment was stainless steel 304 [9] A240/A240M - 14. Stainless steel is known as an iron-chromium-nickel alloy which has good combined mechanical properties and manufacturing characteristics [10]. Stainless steel offers excellent corrosion resistance coupled with exceptional strength, ductility, toughness and formability in cold working to give an extensive range of semi-fabricated and finished products. This material is easily maintained to give an attractive, hygienic and high-tech appearance. The stainless steel sheet metal plate-type tensile test specimens are prepared according to the American Society for Testing and Materials [11] A37012a. Tensile tests were carried out on an Instron universal testing machine [12] with a maximum capacity of $100 \mathrm{kN}$ with a stretch velocity of $2 \mathrm{~mm} / \mathrm{min}$. Experimental data were obtained by the automatic signal acquisition system. Stainless steel 304 sheet metal $(120 \mathrm{~mm} \times 30 \mathrm{~mm})$ cut along the rolling direction was used in this experiment. The thickness of the studied sheet metal was $3 \mathrm{~mm}$. An arc spark optical emissions spectrometer test machine with specified Argon gas of programming type (Fe-30-F) was used to ascertain the chemical composition of the stainless steel. The minimum and maximum heights of the sample were in the range of 2 to $25 \mathrm{~mm}$. The chemical composition of stainless steel 304 is shown in Table 1.

Table 1. Chemical composition of stainless steel 304 (in wt.\%)

\begin{tabular}{ccccccccc}
\hline & $\mathrm{C}$ & $\mathrm{Si}$ & $\mathrm{Mn}$ & $\mathrm{P}$ & $\mathrm{S}$ & $\mathrm{Cr}$ & $\mathrm{Ni}$ & $\mathrm{Mo}$ \\
\hline Stainless Steel & 0.07 & 0.357 & 1.04 & 0.01 & 0.029 & 18.12 & 8.45 & 0.132 \\
\hline
\end{tabular}

The mechanical properties of stainless steel 304 (ASTM A240) shown by the uniaxial tensile test are shown in Table 2. The tensile stress-strain curve of the specimens, measured with a mechanical extensometer, obtained from the tensile test is shown in Figure 1. 
Table 2. The mechanical properties of stainless steel 304.

\begin{tabular}{cccccc}
\hline Material & $\begin{array}{c}\text { Thickness } \\
{[\mathrm{mm}]}\end{array}$ & $\begin{array}{c}\text { YS }_{0.2} \\
{[\mathrm{MPa}]}\end{array}$ & $\begin{array}{c}\text { UTS } \\
{[\mathrm{MPa}]}\end{array}$ & $\begin{array}{c}\text { E } \\
{[\mathrm{Gpa}]}\end{array}$ & $\begin{array}{c}\text { Poisson's } \\
\text { Ratio }\end{array}$ \\
\hline Stainless Steel 304 & 3 & 350 & 620 & 195 & 0.29 \\
\hline
\end{tabular}

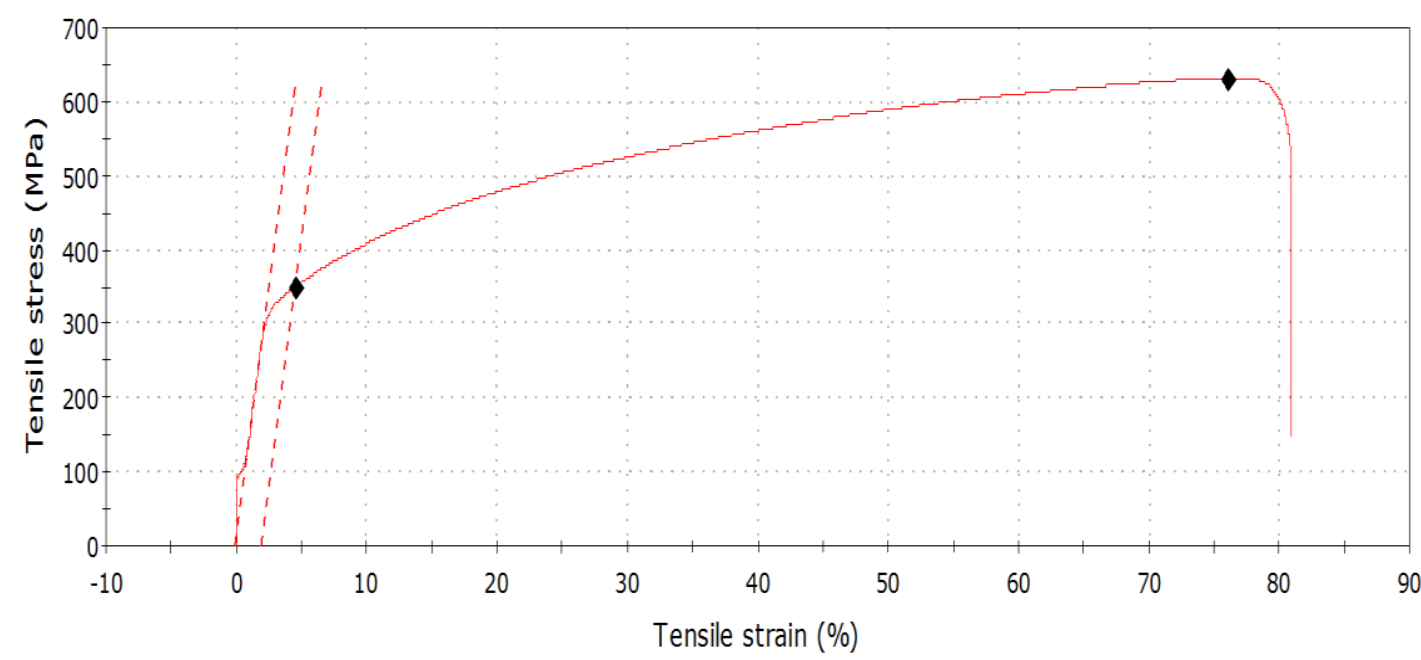

Figure 1. Tensile stress-strain curves of the specimen.

The bending tests were conducted on the same machine with the air V-die free bending tool using several specimens. The velocity of this machine is from $1.6 \times 10^{-03}$ to $8.3 \mathrm{~mm} / \mathrm{s}$ using a desktop computer. This test machine allows various accurate stressdisplacements to be plotted on the desktop computer. A punch and air $\mathrm{V}$ type free bending die with different radii of $5 \mathrm{~mm}, 8 \mathrm{~mm}, 9.5 \mathrm{~mm}$ and $12.5 \mathrm{~mm}$, respectively were used as the bending tools. The selected sizes of the specimens in this experiment are as referred to in previous research $[5,13]$. The punch and die tool set is made from hardened steel. Figure 2 shows the set-up of the test machine with (a) the punch and (b) the die, for which the radius can be changed as needed in the experiment, and (c) a Mitatoyo digital profile projector, which is used to examine the bending angle of every bent part. Two variations in the punch and die radii were used to analyze the effect of the die and punch radii on the springback, as given in Table 3.

Table 3. Variations in punch and die radii

\begin{tabular}{|c|c|c|c|c|c|c|}
\hline & Parameters & $\begin{array}{l}\text { Punch } \\
\text { radius } \\
(\mathrm{mm}) \\
\end{array}$ & $\begin{array}{c}\text { Die } \\
\text { radius } \\
(\mathrm{mm}) \\
\end{array}$ & $\begin{array}{c}\text { Die gap } \\
(\mathrm{mm})\end{array}$ & $\begin{array}{c}\text { Punch } \\
\text { travel } \\
(\mathrm{mm}) \\
\end{array}$ & $\begin{array}{c}\text { Punch } \\
\text { velocity } \\
(\mathrm{mm} / \mathrm{min})\end{array}$ \\
\hline \multirow{4}{*}{ 壳 } & Variation in die radius $\left(R_{d}\right)$ & & 5 & \multirow{8}{*}{80} & \multirow{8}{*}{18} & \multirow{8}{*}{27} \\
\hline & values with fixed punch radius & 5 & 8 & & & \\
\hline & & & 9.5 & & & \\
\hline & & & 12.5 & & & \\
\hline \multirow{4}{*}{$\stackrel{N}{5}$} & Variation in punch radius $\left(R_{p}\right)$ & 5 & \multirow{4}{*}{5} & & & \\
\hline & values with fixed die radius & 8 & & & & \\
\hline & $\left(R_{d}\right)$ value. & 9.5 & & & & \\
\hline & & 12.5 & & & & \\
\hline
\end{tabular}




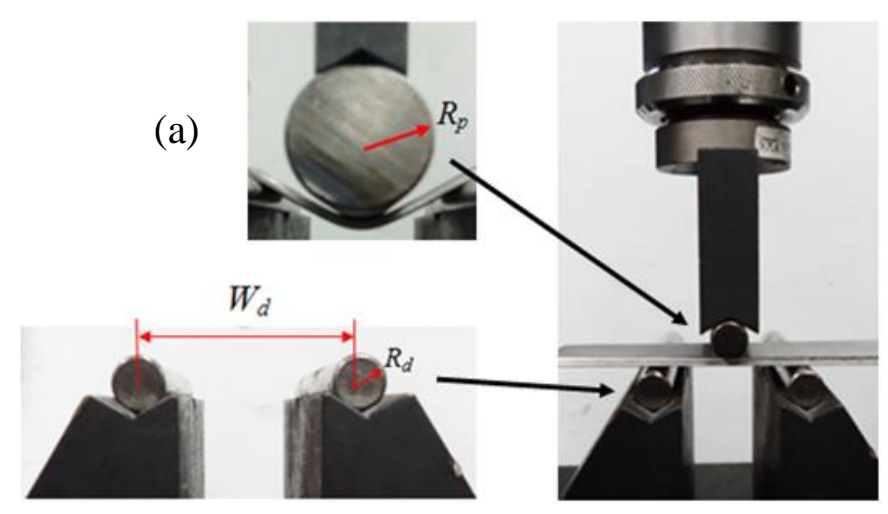

(b)

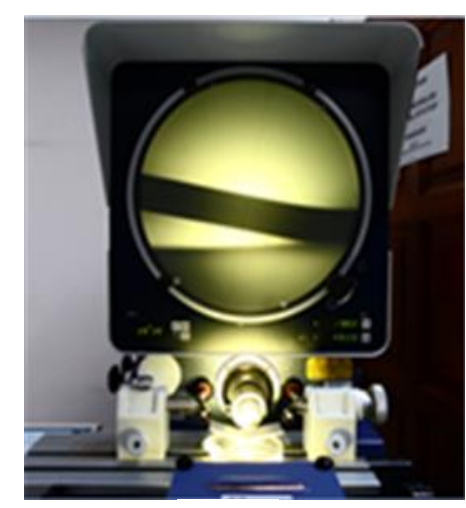

(c)

Figure 2. Picture of the test set up with a UTM $100 \mathrm{kN}$ Instron machine:

(a) punch radius $\left(R_{p}\right)$ and (b) die radius $\left(R_{d}\right)$ with die gap $\left(W_{d}\right)$

(c) Mitatoyo digital profile projector.

Basically, the measurement of the springback refers to the fundamental theory of the bending process itself. The springback amount can be measured by a springback angle $(\Delta \theta)$, which can be calculated using the following equation:

$$
\Delta \theta=\theta_{i}-\theta_{f}
$$

Figure 3 (a) and (b) are photographs of the bending angle in the air bending process during loading and unloading.

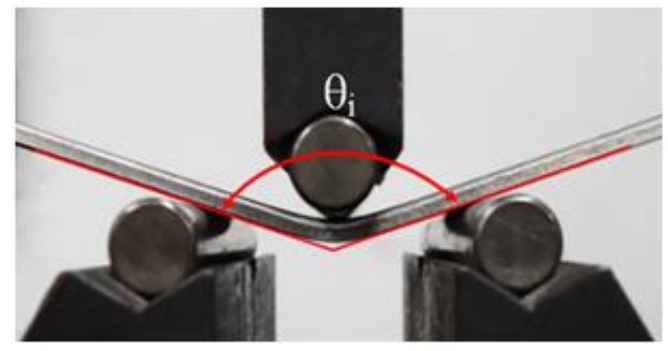

(a)

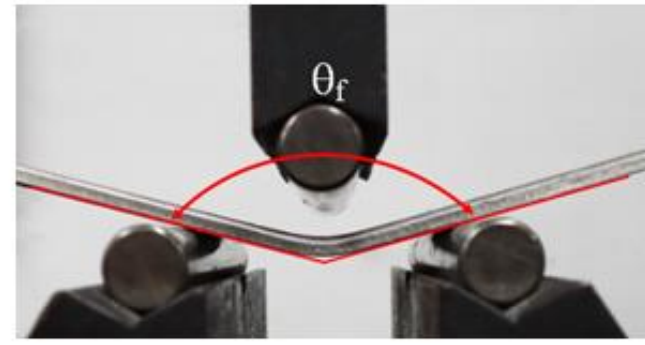

(b)

Figure 3. (a) Bending angle during loading and (b) bending angle after unloading.

\section{Design of Experiment}

The commercial software MINITAB 16 was used as the statistical tool to analyze the data and to systematically investigate the product variables that influence product quality. Five process parameters and a two-level experimental design matrix were chosen and full factorial design $\left(2^{k}\right)$ was applied. The two-level values, $\left(2^{5}\right)$ full factorial design or 32 runs of the specimen tests were undertaken to cover all possible combinations. In this experimental design matrix, the springback is the process response. The ANOVA technique was also applied to illustrate the degree of significance of each process parameter influencing springback in the air V-bending process. The following five process parameters were considered: the die radius $\left(R_{d}\right)$, 
punch radius $\left(R_{p}\right)$, die gap $\left(W_{d}\right)$, punch velocity [14] and punch travel $\left(T_{p}\right)$ within the low and high levels presented in Table 4. The significance level of the factor refers to the statistical $p$ value. The $p$ value for this case is at the 0.05 level of significance $(95 \%$ confidence level). If the $\mathrm{p}$ value is small $<0.05$, it indicates that the power level has a statistically significant effect on the responses [15]. A p value in the range $0-1$, means that, the lower the $\mathrm{p}$ value, the more significant the difference between the groups of factors.

Table 4. The level and value of the DOE parameters.

\begin{tabular}{lcc}
\hline \multicolumn{1}{c}{ Process Parameters } & \multicolumn{2}{c}{ Levels } \\
\cline { 2 - 3 } & $\begin{array}{c}\text { Low } \\
(-1)\end{array}$ & $\begin{array}{c}\text { High } \\
(+1)\end{array}$ \\
\hline Die Radius $\left(R_{d}\right)$ in mm & 5 & 8 \\
Punch Radius $\left(R_{p}\right)$ in mm & 8 & 12.5 \\
Die Gap $\left(W_{d}\right)$ in $\mathrm{mm}$ & 55 & 80 \\
Punch Velocity [14] in mm/m & 27 & 45 \\
Punch Travel $\left(T_{p}\right)$ in $\mathrm{mm}$ & 12 & 18 \\
\hline
\end{tabular}

\section{RESULTS AND DISCUSSION}

Experiments were conducted to evaluate the effectiveness of the punch and die radii influence on the springback affect. As shown in Figures 4 and 5, the influence of the punch and die radii on the springback angle in the air $\mathrm{V}$-bending tests for these two factors have a significant influence on springback. Figures 4 and 5 also clearly show that the punch radius has a more significant impact on springback in air free V-die bending that the die radius. For Set 1 , the effect of the die radius on the springback is shown in Figure 4 which assesses variations in die radius $\left(R_{d}\right)$ with a fixed punch radius $\left(R_{p}\right)$. From the figure it can be seen that the springback increases with the increase in value of the die radius. For die radii of $5 \mathrm{~mm}, 8 \mathrm{~mm}, 9.5 \mathrm{~mm}$ and $12.5 \mathrm{~mm}$ the values of springback are $7.19^{\circ}, 7.21^{\circ}, 7.23^{\circ}$ and $7.25^{\circ}$, respectively. This result agrees with the findings in [15] where the effect of die radius and blank thickness on the springback angle of the flanging process was investigated. In these phenomena, the point of contact between the large area of the die radius and the blank sheet are spaced further apart. This increases the moment arm and hence the bending moment which in turn induces a larger springback angle as explained in [16].

Meanwhile, for Set 2, the effect of punch radius on springback is shown in Figure 5 which assesses the variations in punch radius $\left(R_{p}\right)$ with fixed die radius $\left(\mathrm{R}_{d}\right)$. The figure shows that the springback values increase more the greater the punch radius. For punch radii of $5 \mathrm{~mm}, 8 \mathrm{~mm}, 9.5 \mathrm{~mm}$ and $12.5 \mathrm{~mm}$ the values of springback were $5.20^{\circ}, 6.3^{\circ}, 7.6^{\circ}$ and $8.8^{\circ}$, respectively. Similar observations were made by [17] and [18] who reported their studies on the effect of punch radius on springback. The springback depends on the size of the plastic zone. A smaller punch radius concentrates the force in a narrow area that yields a higher local straining level and greater plastic deformation. In this phenomenon, when the punch radius increases, the force is spread along a large plastic zone thus increasing the springback. 


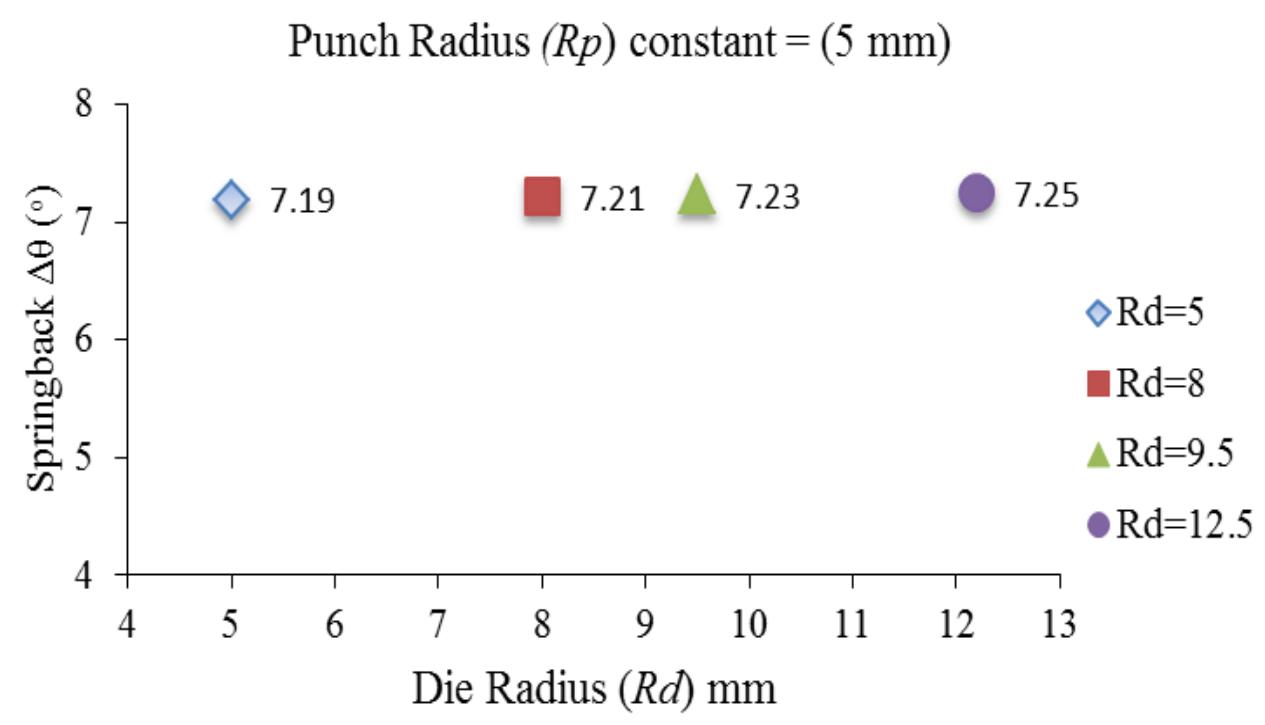

Figure 4. Influence of the die radius $(R d)$ with a fixed punch radius $(R p)$ value of $5 \mathrm{~mm}$ on the springback angle.

Die Radius $(R d)$ constant $=(5 \mathrm{~mm})$

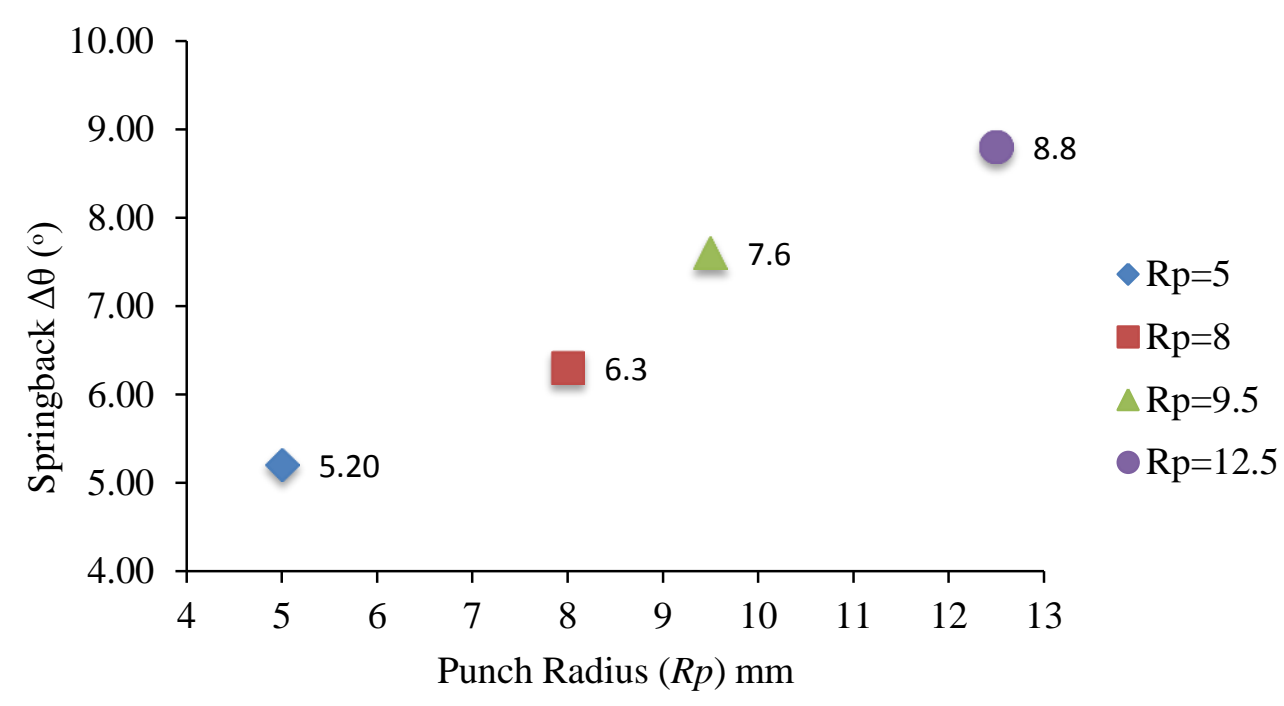

Figure 5. Influence of the punch radius $(R p)$ with a fixed die radius $(R d)$ value of $5 \mathrm{~mm}$ on the springback angle.

The experimental results of the responses from the experimental design matrix are shown in Table 5. The coefficients of the $p$ value of less than 0.05 are considered as significant. The coefficients and $p$ values from the springback analysis are listed in Table 6 which shows that the parameters that strongly affect springback are punch radius, die radius, die gap, punch travel and interaction (die gap and punch travel) with $p$ values of $0.000,0.021,0.000,0.000$ and 0.003 , respectively. Meanwhile, punch velocity is an insignificant parameter. 
Table 5. Design matrix and experimental results of the responses.

\begin{tabular}{|c|c|c|c|c|c|c|}
\hline $\begin{array}{l}\text { No. } \\
\text { Exp. }\end{array}$ & $\begin{array}{c}\text { Punch } \\
\text { Radius } \\
(\mathrm{mm})\end{array}$ & $\begin{array}{c}\text { Die } \\
\text { Radius } \\
(\mathrm{mm})\end{array}$ & $\begin{array}{c}\text { Die } \\
\text { Gap } \\
(\mathrm{mm})\end{array}$ & $\begin{array}{l}\text { Punch } \\
\text { Travel } \\
(\mathrm{mm})\end{array}$ & $\begin{array}{c}\text { Punch } \\
\text { Velocity } \\
(\mathrm{mm} / \mathrm{min})\end{array}$ & $\begin{array}{c}\text { Responses } \\
\left({ }^{\circ}\right)\end{array}$ \\
\hline 1 & 8 & 5 & 55 & 12 & 27 & 4.26 \\
\hline 2 & 12.5 & 5 & 55 & 12 & 27 & 5.16 \\
\hline 3 & 8 & 8 & 55 & 12 & 27 & 5.06 \\
\hline 4 & 12.5 & 8 & 55 & 12 & 27 & 5.18 \\
\hline 5 & 8 & 5 & 80 & 12 & 27 & 4.32 \\
\hline 6 & 12.5 & 5 & 80 & 12 & 27 & 5.22 \\
\hline 7 & 8 & 8 & 80 & 12 & 27 & 5.31 \\
\hline 8 & 12.5 & 8 & 80 & 12 & 27 & 5.75 \\
\hline 9 & 8 & 5 & 55 & 18 & 27 & 6.16 \\
\hline 10 & 12.5 & 5 & 55 & 18 & 27 & 6.80 \\
\hline 11 & 8 & 8 & 55 & 18 & 27 & 6.76 \\
\hline 12 & 12.5 & 8 & 55 & 18 & 27 & 8.00 \\
\hline 13 & 8 & 5 & 80 & 18 & 27 & 5.04 \\
\hline 14 & 12.5 & 5 & 80 & 18 & 27 & 5.93 \\
\hline 15 & 8 & 8 & 80 & 18 & 27 & 5.20 \\
\hline 16 & 12.5 & 8 & 80 & 18 & 27 & 5.69 \\
\hline 17 & 8 & 5 & 55 & 12 & 45 & 4.83 \\
\hline 18 & 12.5 & 5 & 55 & 12 & 45 & 5.58 \\
\hline 19 & 8 & 8 & 55 & 12 & 45 & 4.59 \\
\hline 20 & 12.5 & 8 & 55 & 12 & 45 & 6.63 \\
\hline 21 & 8 & 5 & 80 & 12 & 45 & 4.40 \\
\hline 22 & 12.5 & 5 & 80 & 12 & 45 & 5.39 \\
\hline 23 & 8 & 8 & 80 & 12 & 45 & 4.51 \\
\hline 24 & 12.5 & 8 & 80 & 12 & 45 & 5.20 \\
\hline 25 & 8 & 5 & 55 & 18 & 45 & 5.16 \\
\hline 26 & 12.5 & 5 & 55 & 18 & 45 & 6.50 \\
\hline 27 & 8 & 8 & 55 & 18 & 45 & 6.54 \\
\hline 28 & 12.5 & 8 & 55 & 18 & 45 & 6.85 \\
\hline 29 & 8 & 5 & 80 & 18 & 45 & 5.54 \\
\hline 30 & 12.5 & 5 & 80 & 18 & 45 & 5.60 \\
\hline 31 & 8 & 8 & 80 & 18 & 45 & 5.13 \\
\hline 32 & 12.5 & 8 & 80 & 18 & 45 & 5.49 \\
\hline
\end{tabular}

The significant effect of each parameter, evaluated by plotting the percent against the standardized effect of the springback, is shown in Figure 6. From Figure 6 it can be seen that the parameters such as punch radius, die radius, die gap, punch travel and interaction die gap, and punch travel are significant factors affecting springback but punch velocity is not significant. The main influencing effects of the punch radius and die radius on springback are plotted as shown in Figure 7. 
Table 6. Estimated springback effects and coefficients.

\begin{tabular}{lcccc}
\hline \multicolumn{1}{c}{ Term } & Effect & Coefficient & Term & $p$ value \\
\hline Constant & & 5.5554 & 72.99 & 0.000 \\
Punch Radius & 0.7592 & 0.3796 & 4.99 & 0.000 \\
Die Radius & 0.3746 & 0.1873 & 2.46 & 0.021 \\
Die Gap & -0.6458 & -0.3229 & -4.24 & 0.000 \\
Punch Travel & 0.9374 & 0.4687 & 6.16 & 0.000 \\
Punch Velocity & -0.1191 & -0.0595 & -0.75 & 0.466 \\
Die Gap \&Punch Travel & -0.4974 & -0.2487 & -3.27 & 0.003 \\
\hline
\end{tabular}

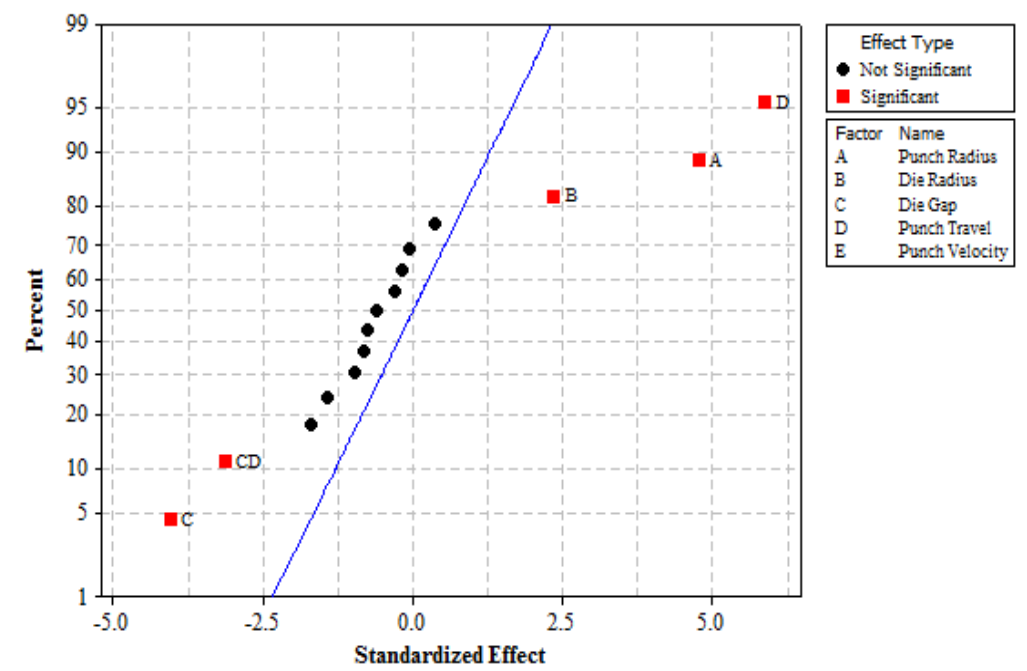

Figure 6. Parameters affecting springback.

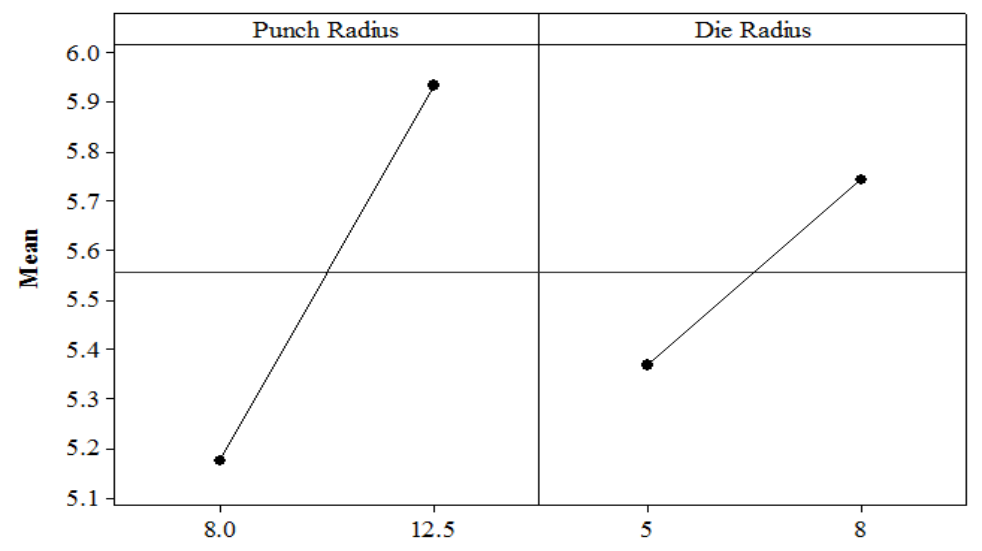

Figure 7. Plots of the main effects of the influencing parameters on springback.

The main effect plots were generated to represent the results of the regression analysis. They show only the factors that were significant at the $95 \%$ confidence interval. The main effects represent deviations in the average between the high and low levels for each factor. When the effect of a factor is positive, springback increases as the factor level changes from low to high. In contrast, if the effects are negative, a reduction in springback occurs from levels high to low of the same factor [19]. From the figures, 
the effects of the punch and die radii are positive, that is, an increase in springback is observed when the factor changes from low to high. High level punch and die radii result in a higher mean springback compared to their low levels. In addition, the punch radius had a greater effect on springback, as is evident by the longer vertical line as compared to the die radius.

\section{CONCLUSIONS}

Using two sets of experiments and the DOE method, the results show that punch and die radii are significance factors affecting springback in stainless steel sheet metal in air $\mathrm{V}$ die free bending. ANOVA and full factorial design $\left(2^{k}\right)$, with five process parameters and two-level values $\left(2^{5}\right)$, were used so that the total number of experiments was 32 . From the analysis and the results of the experiments, it can be concluded that the punch radius is a more significance factor affecting springback. Springback increases with the increase in the punch and die radii. In the air V-die free bending process, the punch radius is the most important factor to be considered. The experimental method agreed well with the DOE results.

\section{ACKNOWLEDGEMENTS}

The authors would like to thank the Faculty of Mechanical Engineering, Universiti Teknologi MARA (UiTM) Shah Alam, Malaysia for financial support under 600RMI/DANA 5/3/PSI (361/2013) and Department of Polytechnic Education, Minister of Education Malaysia.

\section{REFERENCES}

[1] Dilip Kumar K, Appukuttan KK, Neelakantha VL, Naik PS. Experimental determination of spring back and thinning effect of aluminum sheet metal during L-bending operation. Materials \& Design. 2014;56:613-9.

[2] Vasudevan D, Srinivasan R, Padmanabhan P. Effect of process parameters on springback behaviour during air bending of electrogalvanised steel sheet. Journal of Zhejiang University Science A. 2011;12:183-9.

[3] Osman MA, Shazly M, El-Mokaddem A. Springback prediction in V-die bending: modelling and experimentation. Journal of Achievements in Materials and Manufacturing Engineering. 2010;38:8.

[4] Shah JR, Sharma SK, Patel BC. Investigating Springback effect in U-Die Bending Process by varying different Parameters. Nirma University International Conference on Engineering. Institute of Technology, Nirma University, Ahmedabad. 2011;1-6.

[5] Wang J, Verma S, Alexander R, Gau J-T. Springback control of sheet metal air bending process. Journal of Manufacturing Processes. 2008;10:21-7.

[6] Asgari SA, Pereira M, Rolfe BF, Dingle M, Hodgson PD. Statistical analysis of finite element modeling in sheet metal forming and springback analysis. Journal of Materials Processing Technology. 2008;203:129-36.

[7] Thipprakmas S, Phanitwong W. Process parameter design of spring-back and spring-go in V-bending process using Taguchi technique. Materials \& Design. 2011;32:4430-6. 
[8] Srinivasan R, Vasudevan D, Padmanabhan P. Prediction of bend force and bend angle in air bending of electrogalvanized steel using response surface methodology. Journal of Mechanical Science and Technology. 2013;27:2093105.

[9] ASTM. A240/A240M - 14,. Annual Book of ASTM Standards. American Society for Testing and Materials, West Conshohocken, Pennsylvania.

[10] Bong HJ, Barlat F, Ahn DC, Kim H-Y, Lee M-G. Formability of austenitic and ferritic stainless steels at warm forming temperature. International Journal of Mechanical Sciences. 2013;75:94-109.

[11] ASTM. A370 - 12a,. Annual Book of ASTM Standards. American Society for Testing and Materials, West Conshohocken, Pennsylvania.

[12] Duwig C, Stankovic D, Fuchs L, Li G, Gutmark E. Experimental and numerical study of flameless combustion in a model gas turbine combustor. Combustion Science and Technology. 2007;180:279-95.

[13] Inamdar M, Date P, Narasimhan K, Maiti S, Singh U. Development of an artificial neural network to predict springback in air vee bending. The International Journal of Advanced Manufacturing Technology. 2000;16:376-81.

[14] Tripathi R, Dogra A, Srivastava A, Awana V, Kotnala R, Bhalla G, et al. Influence of sintering temperature and oxygen annealing on transport properties of La0. 67Ca0. 33MnO3. Journal of Physics D: Applied Physics. 2009;42:025003.

[15] Kazan R, Firat M, Tiryaki AE. Prediction of springback in wipe-bending process of sheet metal using neural network. Materials \& Design. 2009;30:418-23.

[16] Garcia-Romeu ML, Ciurana J, Ferrer I. Springback determination of sheet metals in an air bending process based on an experimental work. Journal of Materials Processing Technology. 2007;191:174-7.

[17] Bakhshi-Jooybari M, Rahmani B, Daeezadeh V, Gorji A. The study of springback of CK67 steel sheet in V-die and U-die bending processes. Materials \& Design. 2009;30:2410-9.

[18] Farsi MA, Arezoo B. Bending Force and Spring-Back in V-Die-Bending of Perforated Sheet-Metal Components. Journal of the Brazilian Society of Mechanical Sciences and Engineering. 2011;XXXIII:45-51.

[19] Ponnusami V, Krithika V, Madhuram R, Srivastava SN. Biosorption of reactive dye using acid-treated rice husk: Factorial design analysis. Journal of Hazardous Materials. 2007;142:397-403. 